05.1

\title{
Формирование сверхтвердых покрытий в процессе обработки низкотемпературной плазмой азота в открытой атмосфере пленок титана
}

\author{
() М.Х. Гаджиев ${ }^{1}$, Р.М. Эмиров ${ }^{2}$, А.Э. Муслимов ${ }^{3, \uparrow, ~ М . Г . ~ И с м а и л о в ~}{ }^{2}$, В.М. Каневский ${ }^{3}$ \\ ${ }^{1}$ Объединенный институт высоких температур РАН, Москва, Россия \\ ${ }^{2}$ Дагестанский государственный университет, Махачкала, Россия \\ ${ }^{3}$ Федеральный научно-исследовательский центр „Кристаллография и фотоника“ РАН, Москва, Россия \\ IE-mail: amuslimov@mail.ru
}

Поступило в Редакцию 11 января 2021г.

В окончательной редакции 12 февраля 2021 r.

Принято к публикации 13 февраля 2021 г.

\begin{abstract}
Приводятся результаты исследования процессов формирования сверхтвердых покрытий путем обработки потоком низкотемпературной плазмы азота в открытой атмосфере пленок титана на подложках сапфира. Показано, что в процессе плазменной обработки формируется покрытие азотсодержащего $\mathrm{TiO}_{2}$ со структурой рутила с двукратным увеличением (в сравнении с рутилом $\mathrm{TiO}_{2}$ ) микротвердости (до $27 \mathrm{GPa}$ ). Нанесение данного покрытия приводит к упрочнению поверхности сапфировых пластин на $22-23 \%$. Высокая производительность и осуществление синтеза в открытой атмосфере позволяют рассматривать предложенную методику как перспективную для получения сверхтвердых покрытий с высокой резистентностью к кислороду.
\end{abstract}

Ключевые слова: рутил, сапфир, титан, низкотемпературная плазма, азот, микротвердость.

DOI: 10.21883/PJTF.2021.09.50908.18701

Современные технологии, в том числе машиностроение, военные технологии, медицина, транспорт, электроника, немыслимы без использования сверхтвердых материалов. При этом важным требованием является способность сверхтвердых материалов сохранять высокие механические и теплофизические свойства при длительной высокотемпературной эксплуатации в кислородной атмосфере. Этому комплексу требований могут отвечать азотсодержащие оксиды, или оксинитриды, титана. Дело в том, что среди основных фаз диоксида титана, встречающихся в природе (анатаз, брукит и рутил), наибольшей микротвердостью обладает последняя (порядка $14 \mathrm{GPa}$ ) [1-3]. Как показали результаты работы [4], это не является пределом. При давлении 60-70 GPa и температуре $1100 \mathrm{~K}$ была получена фаза диоксида титана со структурой котунита, которая демонстрировала микротвердость $38 \mathrm{GPa}$. Полученный уникальный результат объясняется корреляцией микротвердости с величиной сжимающих остаточных напряжений. С другой стороны, известен [5] способ упрочнения титановых сплавов, основанный на их азотировании. Однозначной интерпретации упрочняющего влияния азотирования на различные сплавы сегодня не существует. Например, в [6] влияние примеси азота на механические свойства оксидов титана связывается с сегрегацией оксидов азота, в частности $\mathrm{NO}$ и $\mathrm{NO}_{2}$, на границах зерен, которые тормозят процесс их разрастания. Также отмечается преимущественное смещение в сторону образования фазы рутила в процессе синтеза азотсодержащих пленок диоксида титана. Для оксинитридов $\mathrm{TiN}_{z} \mathrm{O}_{y}$ максимальная величина микротвердости [6] достигается при избыточном содержании азота $(z=0.58, y=0.39)$. Для удовлетворения требованиям высокой резистентности к кислороду желательно преобладание кислородсодержащей фазы. Как нам представляется, обработка с использованием низкотемпературной азотной плазмы в открытой атмосфере предварительно осажденных титановых слоев позволит формировать кислородно-резистентное сверхтвердое покрытие. Во-первых, присутствие азота и проведение процесса синтеза в открытой атмосфере приведут к преимущественному формированию в покрытии рутиловой макрофазы, обладающей максимальной микротвердостью. Во-вторых, титан является сильным нитридобразующим элементом, и возможно образование в объеме покрытия микровключений низшего нитрида $\mathrm{Ti}_{2} \mathrm{~N}$ и мононитрида титана TiN, отличающихся высокой микротвердостью до $28 \mathrm{GPa}$ [7]. Более того, высокая диффузионная активность азота приведет к близкому к однородному (по объему покрытия) распределению азота. С другой стороны, при плазменном азотировании в открытой атмосфере фронт окисления и нитридизации распространяется от поверхности пленки к подложке. С учетом высокой скорости протекания термохимических процессов при плазменной обработке следует ожидать значительных сжимающих напряжений в объеме покрытия. Дополнительными преимуществами использования методики плазменной обработки в открытой атмосфере являются ее высокая производительность, отсутствие специфических условий, связанных с необходимостью поддержания различных уровней вакуума.

В настоящей работе представлены результаты исследования процессов формирования сверхтвердого покры- 

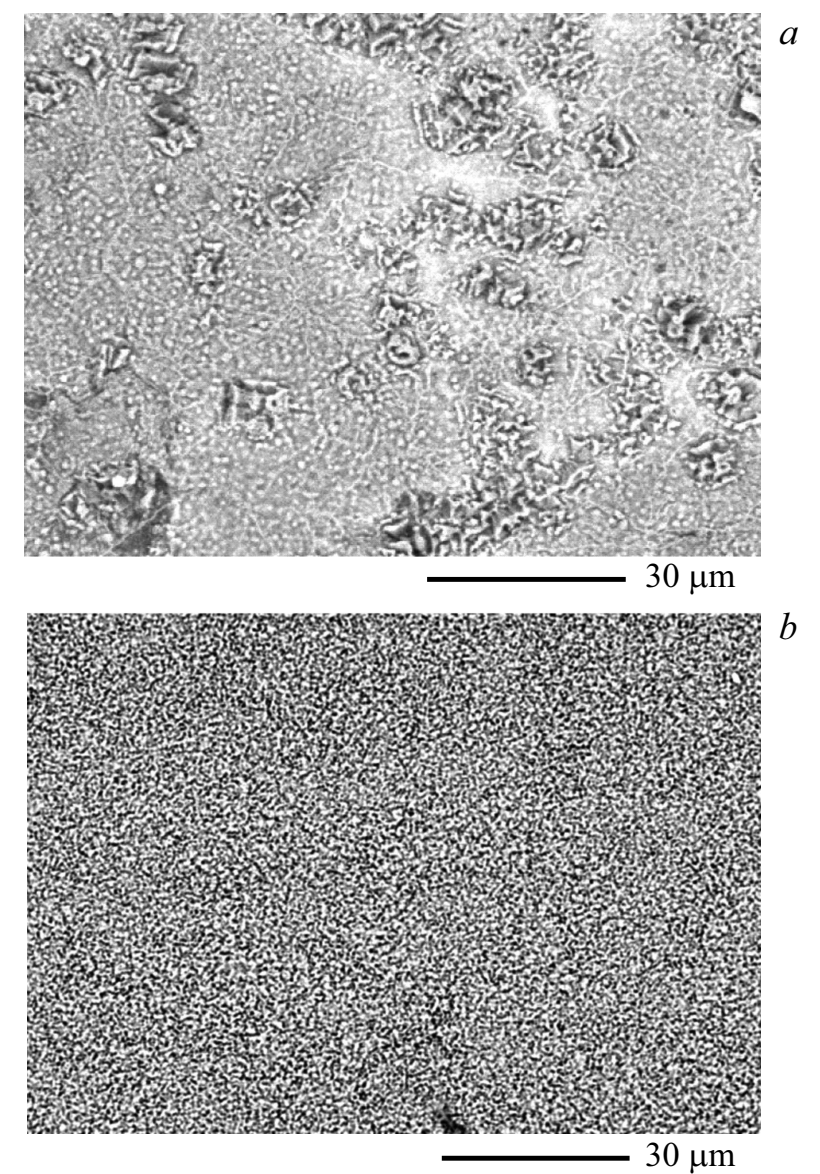

Рис. 1. Электронно-микроскопические изображения поверхности: покрытия на основе алюминия $(a)$ и титана $(b)$ на сапфире после обработки в азотной плазме.

тия в процессе обработки в потоке низкотемпературной плазмы азота в открытой атмосфере пленок титана на подложках сапфира и изучения их механических свойств.

В качестве образцов для исследования использовались пленки титана, нанесенные на подложки сапфира методом магнетронного распыления на автоматизированном магнетронном комплексе „ВАТТ АМК-МИ“ [8]. Обработка пленок низкотемпературной высокоэнтальпийной плазмой азота проводилась по методике, описанной в $[9,10]$. Основные параметры были следующими: энтальпия до $50 \mathrm{~kJ} / \mathrm{g}$, среднемассовая температура $7-10 \mathrm{kK}$, электрическая мощность дугового разряда $20-50 \mathrm{~kW}$. Использовался режим со значительной атомарной составляющей в плазме. Рентгенограммы снимались на дифрактометре Empyrean фирмы PANalytical (Нидерланды) в геометрии Брэгга-Брентано. Использовалось излучение от медного анода $\left(\mathrm{Cu} K_{\alpha 2}=1.54 \AA\right)$. Анализ дифрактограмм и идентификация пиков осуществлялись в программе High Score Plus с использованием базы данных ICSD (PDF-2). Микроскопические исследования проводились на растровом электронном микроскопе JEOL, оснащенном энергодисперсионным микроанали- затором. Твердость образцов исследовалась с помощью сканирующего нанотвердомера НаноСкан-3D (Тиснум, Троицк). Значение микротвердости для образцов определялось методом динамического индентирования. Величина микротвердости по Виккерсу рассчитывалась усреднением по числу вдавливаний индентора в области $50 \times 50 \mu \mathrm{m} \mathrm{c}$ нагрузкой от 1 до $50 \mathrm{mN}$. Для сравнения в работе использовались исходная подложка сапфира $c$-ориентации и пленка алюминия на сапфире после обработки в плазме азота.

В процессе обработки в течение $1 \mathrm{~min}$ в азотной плазме в открытой атмосфере на подложках сапфира формировались покрытия на основе алюминия и титана с высоким содержанием кислорода. В обоих случаях наблюдалась зернистая пленка, однако микроморфология поверхности образцов значительно различалась. Поверхность пленки алюминия после обработки была морфологически неоднородной (рис. 1,a): на фоне сплошной пленки выделялись кластеры с размерами до нескольких десятков микрометров. В противоположность этому поверхность пленки титана после обработки была однородной (рис. $1, b)$.

На первоначальном этапе исследовалась микротвердость поверхности сапфировой подложки $c$-ориентации. Согласно полученным данным (рис. 2, a, кривая 1), на величину микротвердости сапфировой подложки сильно
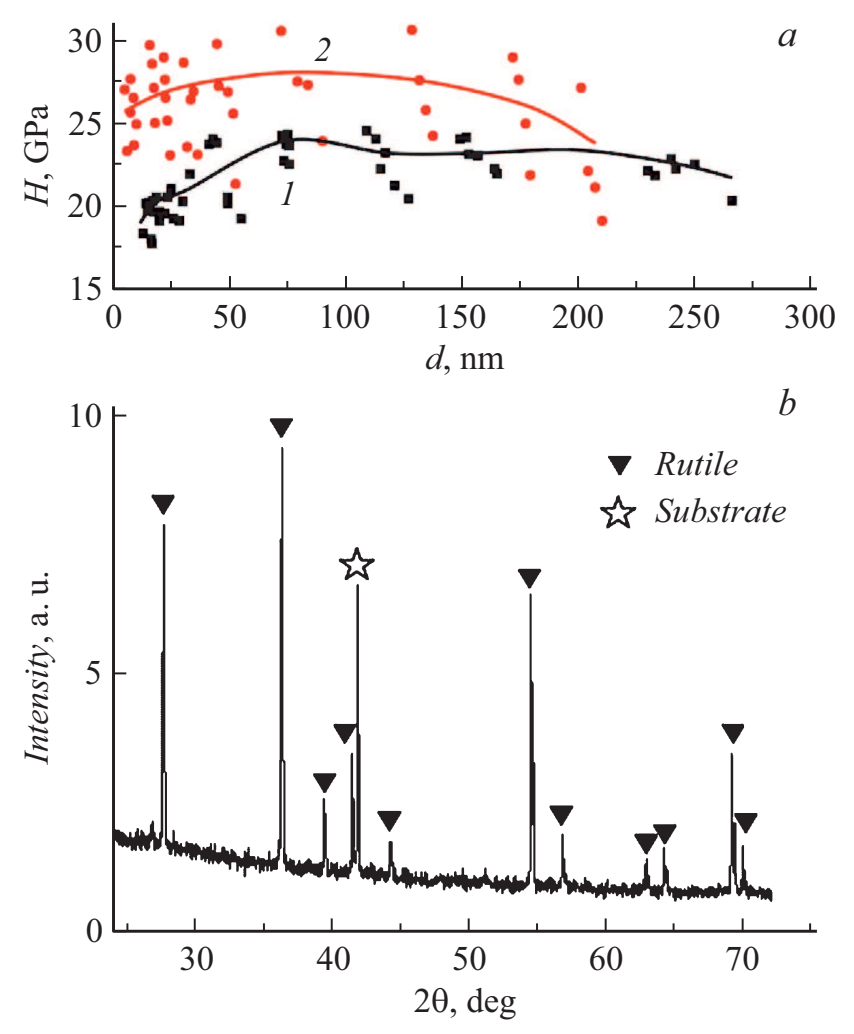

Рис. 2. Зависимость микротвердости от глубины отпечатка покрытия $(a)$ и рентгенограмма $(b)$ азотсодержащего диоксида титана на сапфире. 1 - сапфир, 2 - азотсодержащий диоксид титана. База данных ICSD (PDF-2), номер карточки 98-0024277. 
Элементный состав по данным микроанализа покрытия азотсодержащего диоксида титана на сапфире

\begin{tabular}{c|c}
\hline Элемент & $\begin{array}{c}\text { Содержание, at.\% } \\
( \pm 0.5)\end{array}$ \\
\hline $\mathrm{O}$ & 81.64 \\
$\mathrm{Al}$ & 1.45 \\
$\mathrm{~N}$ & 5.79 \\
$\mathrm{Ti}$ & 11.12
\end{tabular}

влияют поверхностные эффекты и необходимо проводить оценку усреднением по числу вдавливаний индентора на двух участках: на глубине отпечатка менее $50 \mathrm{~nm}$ и более $50 \mathrm{~nm}$. Очевидно, объемная твердость сапфира определяется участком на глубинах отпечатка более $50 \mathrm{~nm}$ (рис. 2, $а$, кривая 1) и имеет значение порядка $22 \mathrm{GPa}$. На глубинах отпечатка менее $50 \mathrm{~nm}$ значительное влияние оказывает нарушенный приповерхностный слой, формирующийся в результате химикомеханической обработки поверхности сапфировой подложки. Твердость (нанотвердость) приповерхностного слоя при этом снижается до $20 \mathrm{GPa}$.

Для пленки алюминия, обработанной в азоте, измеренное значение микротвердости оказалось очень низким (порядка $3.9 \mathrm{GPa}$ ). Наиболее интересный результат был получен при измерении микротвердости обработанной в плазме пленки титана (рис. 2, $a$, кривая 2). $\mathrm{Ee}$ значение при усреднении по числу вдавливаний индентора в интервале глубин отпечатка 50-200 nm, превосходило $27 \mathrm{GPa}$, что на 22-23\% выше величины микротвердости сапфировой пластины. Поиск методов упрочнения поверхности сапфировых стекол является весьма актуальной задачей, и полученный результат может иметь большое прикладное значение.

В полученных покрытиях наблюдалось избыточное содержание кислорода (см. таблицу). Данный факт объясняется более высокой химической активностью кислорода. Энергичное взаимодействие алюминия, титана с кислородом начинается уже при температуре выше $500-600^{\circ} \mathrm{C}$, в то время как процессы нитридизации заметно усиливаются при температуре выше $800^{\circ} \mathrm{C}$. Мелкозернистость и морфологическая однородность азотированной пленки титана (рис. 1,b) обусловлены перескакиванием этапа кластеризации титана в объеме покрытия, поскольку температура плавления титана $\left(1668^{\circ} \mathrm{C}\right)$ значительно выше температур активации процессов окисления и нитридизации. В случае применения пленок алюминия, температура плавления которого значительно ниже $\left(660^{\circ} \mathrm{C}\right)$, плазменная обработка приводит к кластеризации алюминия в более глубоких слоях, не успевающих вступать в реакцию с активными компонентами газа. Следует учитывать, что физико-химические процессы при плазменной обработке протекают в условиях, далеких от термодинамического равновесия. Сами процессы характеризуются высокой гетерогенностью. В случае присутствия этапа кластеризации это может привести к пористости, что отражается в микроморфологии (рис. 1, $a$ ) и значительно снижает по сравнению с сапфиром величину микротвердости покрытия на основе алюминия.

При объяснении высокого значения микротвердости покрытия на основе титана следует учитывать высокую диффузионную активность атомов кислорода и азота, углубляющихся в направлении от поверхности в объем с последовательным образованием слоев $\mathrm{Ti}(\mathrm{O}, \mathrm{N})$. Данное обстоятельство может являться причиной возникновения сжимающих напряжений в объеме покрытия. В общем случае процессы окисления и нитридизации титана отличаются встречной диффузией атомов титана из объема к поверхности преформы и атомов кислорода с азотом в обратном направлении. Указанные особенности при отсутствии кластеризации в объеме покрытия приводят к однородности по глубине, что отражается в сравнительно плавном ходе кривой (рис. 2, a, кривая 2).

Данные рентгеновской дифракции (рис. 2, $b$ ) свидетельствуют о монофазности получаемого покрытия, что, несомненно, обеспечивает стабильность структуры и свойств при высоких температурах. С учетом данных микроанализа (см. таблицу), свидетельствующих об избыточном содержании кислорода, высокой температуры синтеза в присутствии азота можно полагать, что макрофаза покрытия сформирована азотсодержащей фазой рутила $\mathrm{TiO}_{2}$. Относительно высоких значений микротвердости известно [11], что структура рутила имеет более плотную упаковку $\left(4.250 \mathrm{~g} / \mathrm{cm}^{3}\right)$ по сравнению со структурой анатаза $\left(3.899 \mathrm{~g} / \mathrm{cm}^{3}\right)$. Точно так же вероятна сегрегация атомов азота на границах зерен. Скопление азота на границах зерен приводит к сдерживанию миграции границ и межзеренного скольжения. Точно так же снижается подвижность дислокаций. Можно предположить формирование в объеме микровключений типа $\mathrm{Ti}_{2} \mathrm{~N}$, TiN с высокими значениями микротвердости, однако результаты работы [6] свидетельствуют об отсутствии нитридов титана в пленках даже при значительных концентрациях легирующей примеси азота.

Покрытие, синтезируемое в процессе плазменной (азотной) обработки в открытой атмосфере пленок титана, представляет собой азотсодержащую фазу диоксида титана со структурой рутила. Компактная структура (рутил), мелкозернистость (закон Холла-Петча), сегрегация азота на границах зерен, а также сжимающие напряжения в комплексе определяют высокую микротвердость покрытия азотсодержащего диоксида титана.

\section{Финансирование работы}

Исследования проводились в рамках выполнения работ по государственному заданию ФНИЦ „Кристаллография и фотоника“ РАН в части получения сверхтвердых покрытий, по государственному заданию ФГБУ ОИВТ РАН в части воздействия плазмы азота, а также при поддержке Российского фонда фундаментальных 
исследований (грант № 20-0800598). Рентгенофазовый анализ покрытия проводился при частичной поддержке государственного задания FZNZ-2020-0002.

\section{Конфликт интересов}

Авторы заявляют, что у них нет конфликта интересов.

\section{Список литературы}

[1] D. Wojcieszak, M. Mazur, J. Indyka, A. Jurkowska, M. Kalisz, P. Domanowski, D. Kaczmarek, J. Domaradzki, Mater. Sci.Poland, 33 (3), 660 (2015). DOI: 10.1515/msp-2015-0084

[2] K. Yamaguchi, Y. Konaka, N. Ohtsu, Surf. Coat. Technol., 386, 125424 (2020). doi.org/10.1016/j.surfcoat.2020.125424

[3] D. Kaczmarek, J. Domaradzki, D. Wojcieszak, E. Prociow, M. Mazur, F. Placido, S. Lapp, J. Nano Res., 18-19, 195 (2012). DOI: 10.4028/www.scientific.net/JNanoR.18-19.195

[4] L.S. Dubrovinsky, N.A. Dubrovinskaia, V. Swamy, J. Muscat, N.M. Harrison, R. Ahuja, B. Holm, B. Johansson, Nature, 410, 653 (2001). DOI: 10.1038/35070650

[5] V.V. Budilov, K.N. Ramazanov, Yu.G. Khusainov, I.V. Zolotov, S.V. Starovoitov, J. Eng. Sci. Technol. Rev., 8 (6), 25 (2015).

[6] М.Е. Конищев, О.С. Кузьмин, А.А. Пустовалова, Н.С. Морозова, К.Е. Евдокимов, Р.А. Сурменев, В.Ф. Пичугин, М. Эппле, Изв. вузов. Физика, 56 (10), 35 (2013). [Пер. версия: 10.1007/s11182-014-0154-5].

[7] А.П. Достанко, Д.А. Голосов, С.М. Завадский, С.Н. Мельников, Д.Э. Окоджи, Д.Д. Котинго, Г.М. Рубан, ПФМТ, № 2 (27), 12 (2016).

[8] В.П. Власов, А.В. Буташин, В.М. Каневский, А.Э. Муслимов, В.А. Бабаев, А.М. Исмаилов, М.Х. Рабаданов, Кристаллография, 59 (3), 467 (2014). DOI: $10.7868 / \mathrm{S} 0023476114030230$

[9] Э.Х. Исакаев, О.А. Синкевич, А.С. Тюфтяев, В.Ф. Чиннов, TBT, 48 (1), 105 (2010).

[10] М.Х. Гаджиев, А.С. Тюфтяев, А.Э. Муслимов, В.М. Каневский, А.М. Исмаилов, В.А. Бабаев, Письма в ЖТФ, 45 (22), 3 (2019). DOI: 10.21883/PJTF.2019.22.48639.17951

[11] A. Navrotsky, O.J. Kleppa, J. Am. Ceram. Soc., 50 (11), 626 (1967). https://doi.org/10.1111/j.1151-2916.1967.tb15013.x 